\title{
Ventriculo-peritoneal shunt blockage due to ruptured intracerebral dermoid cyst
}

\author{
Ahmad Abu-Omar, Rupert Price
}

\begin{abstract}
Introduction: Intracranial dermoid cysts are rare congenital lesions that can rupture and disseminate intracranially. We present a unique case of a ruptured dermoid cyst leading to blockage of ventriculo-peritoneal shunts. Case Report: A 19-year-old female presented with clumsiness, gait disturbance and occipital headache. Examination revealed an ataxic gait, positive Romberg's sign, lateral gaze nystagmus and hyper-reflexia in all four limbs with bilateral positive Hoffman's sign. A Magnetic resonance scan revealed a large, heterogeneous midline cerebellar mass which had evidently ruptured at some point causing diffuse subarachnoid dissemination of fat. The patient underwent an uneventful posterior fossa craniectomy for removal of the cyst and was discharged home. She presented ten weeks later with headaches, ataxia, vomiting and decreased Glasgow Coma Scale. A cranial computed tomography (CT) scan showed ventriculomegaly which was treated with
\end{abstract}

Ahmad Abu-Omar ${ }^{1}$, Rupert Price ${ }^{2}$

Affiliations: ${ }^{1}$ Specialty Registrar in ENT, Department of Otolaryngology, Crosshouse Hospital, Kilmarnock, UK; ${ }^{2}$ Consultant Neurosurgeon, Department of Neurosurgery, University Hospital of North Staffordshire, Stoke-onTrent, UK.

Corresponding Author: Ahmad Abu-Omar, Department of Otolaryngology, Level 5, Crosshouse Hospital, Kilmarnock Road, Kilmarnock, KA2 0BE, United Kingdom; Phone: 00447792462582; Fax: 00441563827974; Email: aomar@doctors.org.uk

Received: 18 November 2010

Accepted: 04 January 2011

Published: 01 September 2011 insertion of an external ventricular drain. The patient improved but attempts to clamp the external ventricular drain led to recurrence of symptoms. The patient underwent serial operations for ventriculo-peritoneal shunt insertion, but each time symptoms and Glasgow Coma Scale improved only temporarily. This was postulated to be due to free-floating intraventricular fat repeatedly clogging the shunts. Following endoscopic aspiration of the intraventricular lipoid material from the frontal horn before the final shunt revision, there has been no further symptomatic hydrocephalus. Conclusion: Fat dissemination from ruptured intracranial dermoid cysts can lead to blockage of ventriculo-peritoneal shunts. We recommend the removal of intraventricular fat from the outset if cerebrospinal fluid diversion is required.

Keywords: Congenital, Dermoid cyst, Intracranial, Rupture

$* * * * * * * *$

Abu-Omar A, Price R. Ventriculo-peritoneal shunt blockage due to ruptured intracerebral dermoid cyst. International Journal of Case Reports and Images 2011;2(9):9-12.

\section{$* * * * * * * * *$}

doi:10.5348/ijcri-2011-09-53-CR-3

\section{INTRODUCTION}

Dermoid cysts are benign congenital cysts that account for $0.3 \%$ of all brain tumors $[1,2]$. They are 
usually sporadic and up to half of all patients with dermoid cysts have additional congenital anomalies. Dermoid cysts are thought to arise from defects in the separation of the neuroectoderm during the formation of the neural tube, leading to sequestration of ectodermal remnants. They are characterized pathologically by a thick wall of stratified squamous epithelium containing dermal elements [3]. Most dermoid cysts are located in the midline and up to one third are associated with dermal sinus tracts [4]. Intracranial dermoid cysts are well circumscribed and often occur in the parasellar region, sylvian fissure, cerebellopontine angle, posterior fossa, and fourth ventricle $[1,2]$. Patients usually present with headaches, seizures, sensory or motor hemi-syndrome and chemical meningitis [5].

Dermoid cysts often appear as non-enhancing, hypodense lesions on CT scan while MR imaging demonstrates an increased $\mathrm{T} 1$ and variable $\mathrm{T} 2-$ weighted signal [6]. Dermoid cysts contain fat [5], and it is well recognized that they can rupture spontaneously, spreading contents widely throughout the cranium including the ventricles [3].

There is minimal literature relating to blockage of cerebrospinal fluid shunts by lipid contrast agents e.g. Pantopaque [7]. To the best of our knowledge, this has not previously been reported for endogenous sources of lipid. Here we report a case of ventriculo-peritoneal shunt blockage due to the intraventricular lipid following rupture of a posterior fossa dermoid cyst.

\section{CASE REPORT}

A 19-year-old, right-handed female presented via the neurosurgical outpatient department with a history of clumsiness, incoordination and gait disturbance since the age of seven, with recent functional deterioration and the development of occipital headaches. These headaches were constant, exacerbated by coughing and straining, associated with nausea and not relieved by analgesia. Examination revealed an ataxic gait, positive Romberg's test, lateral gaze nystagmus more pronounced to the right side and oscillopsia in upward gaze. Hyper-reflexia was noted in all four limbs with positive Hoffman's sign bilaterally. The patient had been known, since birth, to have a subcutaneous fleshy mass measuring 1x2 $\mathrm{cm}$ just inferior to the torcula; this was thought to be a benign cyst and had not changed significantly in size since early childhood.

An MRI scan of the head and cervical spine revealed a large midline cerebellar tumor $(5 \times 5.7$ x 6.9 $\mathrm{cm}$ ) with heterogenous signal characteristics; there was chemical shift artifact indicating the presence of fat as well as evidence of previous rupture and diffuse subarachnoid / intraventricular dissemination of the fat (Figure 1). The tumor was exerting mass effect on the brainstem and causing mild obstructive triventriculomegaly.

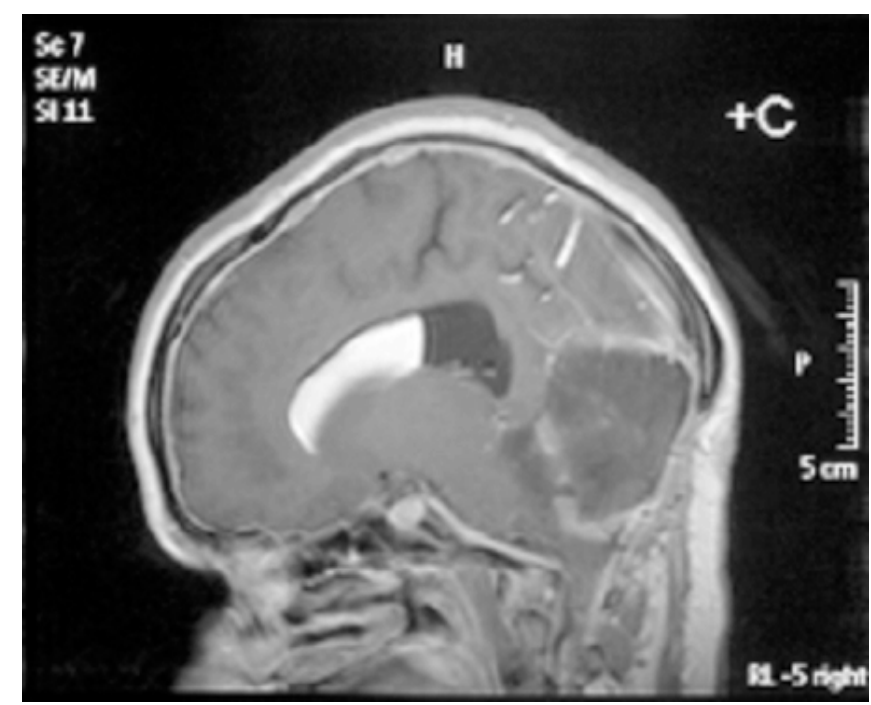

Figure 1: Sagittal T1-weighted MRI scan showing cerebellar tumor and intraventricular fat.

Surgery in the form of a posterior fossa craniectomy and emptying of the cyst with removal of membranes if possible was advised, and this was performed uneventfully in June 2005. The cyst walls were very adherent to the neural structures and could not be removed. The cutaneous mass near the torcula was removed during the approach and both this and the main lesion were confirmed histologically to be dermoid cysts. The patient recovered well and was discharged home on the ninth post-operative day.

Ten weeks later she was readmitted to the emergency with recurrent headache, nausea and vomiting and dramatic worsening of her ataxia over the course of a weekend. Her admission Glasgow Coma Scale (GCS) was 13 (E3 V4 M6) and a cranial CT scan revealed an increase in the ventricular size compared to the pre-operative scans. An external ventricular drain was inserted by the emergency team; the cerebrospinal fluid (CSF) was under significant pressure but microscopic examination and culture were negative. The patient's GCS recovered quickly to 15 with improved neurology, but subsequent attempts to clamp the external ventricular drain led to recurrent symptoms and so it was converted to a ventriculoperitoneal shunt uneventfully. The patient was well for two days, but within a day of beginning to mobilize, she began to complain of recurrent headaches and then dropped her GCS again. A cranial CT scan showed a well-placed ventricular catheter but persistent ventriculomegaly. She was taken for shunt revision, where a blocked ventricular catheter was replaced. She recovered to GCS 15 quickly and remained well for two days, but once again within a day of being mobilised she complained of headaches and dropped her GCS. On this occasion she aspirated and developed significant hypoxia requiring intubation for airway control and toilet. A cranial CT scan again showed 
ventriculomegaly and the shunt was revised for a second time, again finding a blocked proximal end although this time we elected to replace the entire shunt. The patient was managed in the Intensive Care Unit for her chest problems for five days before being successfully extubated and returned to the ward.

At this stage she was GCS 15, headache free but with persistent mild cerebellar signs. We attempted to mobilise her once more, but for the third time this led to recurrent headaches and a drop in her GCS. Once again a cranial CT scan showed ventriculomegaly and shunt revision was clearly required. On this occasion, a two-stage procedure was performed. First, the neuroendoscope was inserted via a right frontal burrhole and approximately $13 \mathrm{mls}$ of yellowish, highly viscid, lipoid material was aspirated from the frontal horn. Interestingly, this proved difficult to do as the material appeared to react with the plastic of the syringes and impede smooth movement of the plunger, such that four or five syringes were needed. When all the fat had been removed, an Ommaya reservoir was placed and the ventriculo-peritoneal shunt was then revised completely once again. Unfortunately, the ventricular catheter and shunt valve, which were to have been kept for microscopic examination, were mislaid in theatre.

As usual, the patient recovered rapidly to GCS 15, headache free, but this time when she was mobilized after a couple of days in bed there was no deterioration and she managed to progress to the regional rehabilitation hospital and eventually to independent life in the community. She has currently been followed up for six years with no further shunt malfunctions and imaging showing normal ventricular size, complete evacuation of the lipid from the right lateral ventricle and no recurrence of the posterior fossa dermoid cyst (Figures 2,3).

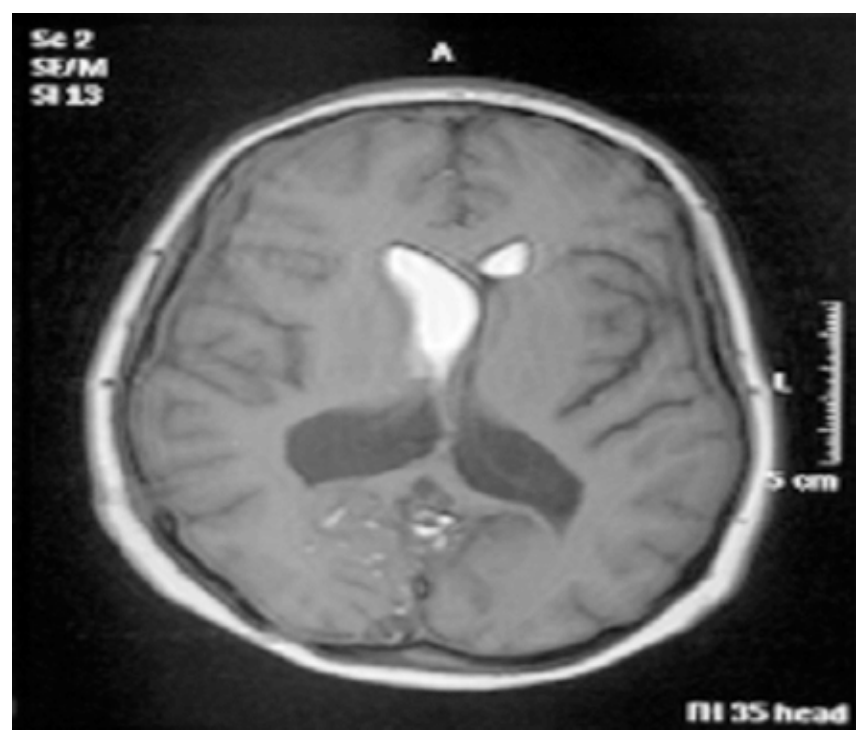

Figure 2: Axial T1-weighted MRI scan showing intraventricular fat in both lateral ventricles and in the cortical sulci.

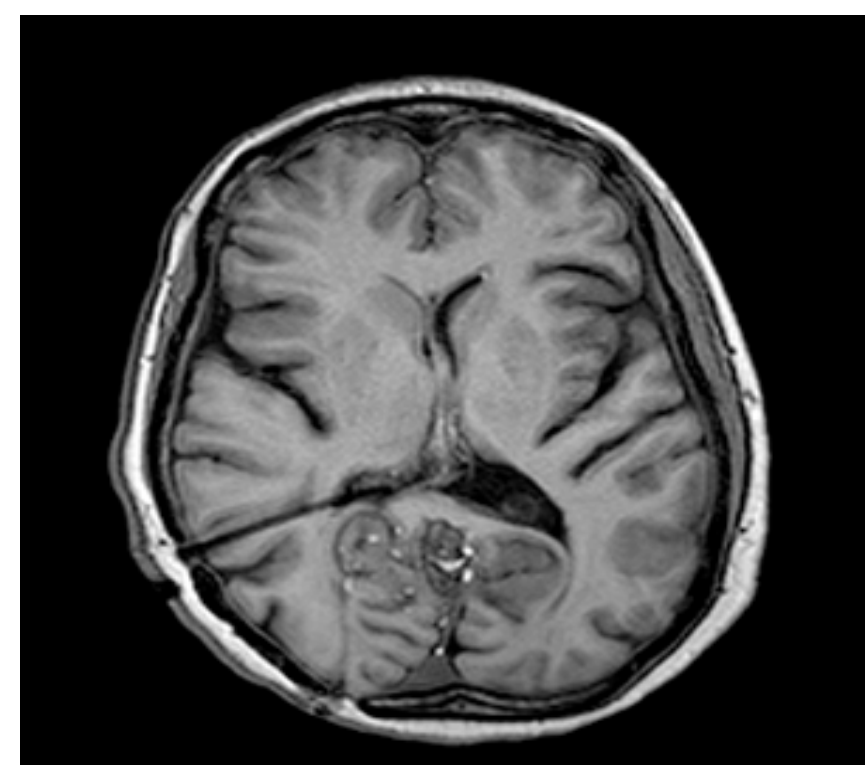

Figure 3: Axial T1-weighted MRI scan showing a functioning right parietal shunt with a decompressed ventricular system. The intraventricular fat has been removed; the cortical sulcal fat remains.

\section{DISCUSSION}

All neurosurgeons work through a long list of potential causes of shunt blockage when managing patients with CSF diversions. We thought initially that this case report would add another cause to that list, namely intraventricular fat, in this case derived from the spontaneous rupture of a dermoid cyst. We were initially at a loss to explain the unusual pattern of repeated shunt obstructions shortly after the patient began to mobilize following shunt insertion/revision, but on the third occasion it did finally occur to us that if the low density fat we could see within the right lateral ventricle was freely mobile, then in the upright posture it might be able to float into the ventricular catheter and/or valve mechanism and interfere with their function, whereas when the patient was supine it floated to the frontal pole where it caused no problems. Although an initial literature search produced no reports of this phenomenon, this case was so troublesome that we elected to remove the fat endoscopically before revising the shunt. The difficulty experienced in aspirating the fat (due to its reaction with the plastic in the plunger), together with the absence of any further shunt malfunctions since its removal supports the underlying hypothesis. Unfortunately we were not able to demonstrate the presence of fat in the ventricular catheter and/or valve mechanism, as these were mislaid in theatre.

Subsequently, a more detailed literature search has found a previous case report of shunt blockage by lipid material (Pantopaque intraventricular contrast agent), [7] and it now transpires that we have merely re- 
discovered a known phenomenon twenty years after the investigation which provoked it fell out of use, albeit that the source of the lipid is different. Whilst it is rare to find intraventricular fat, this case report demonstrates what trouble it can cause, so we would encourage others to consider removing the fat at the outset if CSF diversion is required.

\section{CONCLUSION}

Although this is clearly a very rare event, it can cause significant mischief and is worth bearing in mind when managing similar patients.

$$
* * * * * * * *
$$

\section{Author Contributions}

Ahmad Abu-Omar - Substantial contributions to conception and design, Acquisition of data, Analysis and interpretation of data, Drafting the article, Revising it critically for important intellectual content, Final approval of the version to be published Rupert Price - Substantial contributions to conception and design, Acquisition of data, Analysis and interpretation of data, Drafting the article, Revising it critically for important intellectual content, Final approval of the version to be published

\section{Guarantor}

The corresponding author is the guarantor of submission.

\section{Conflict of Interest}

Authors declare no conflict of interest.

\section{Copyright}

(C) Ahmad Abu-Omar et al. 2011; This article is distributed under the terms of Creative Commons attribution 3.0 License which permits unrestricted use, distribution and reproduction in any means provided the original authors and original publisher are properly credited. (Please see www.ijcasereportsandimages.com /copyright-policy.php for more information.)

\section{REFERENCES}

1. Berger MS, Wilson CB. Epidermoid cysts of the posterior fossa. J Neurosurg. 1985;62:214-9.

2. Gormley WB, Tomecek FJ, Qureshi N, Malik GM. Craniocerebral epidermoid and dermoid tumours: a review of 32 cases. Acta Neurochir 1994;128:115-21.

3. Liu JK, Gottfried ON, Salzman KL, Schmidt RH, Couldwell WT. Ruptured intracranial dermoid cysts: clinical, radiographic, and surgical features. Neurosurgery. 2008;62:377-84.

4. Guidetti B, Gagliardi FM. Epidermoid and dermoid cysts. Clinical evaluation and late surgical results. J
Neurosurg. 1977;47:12-18.

5. Stendel R, Pietilä TA, Lehmann K, Kurth R, Suess O, Brock M. Ruptured intracranial dermoid cysts. Surg Neurol. 2002;57:391-8.

6. Neugroschl C, David P, Sadeghi N, Soebert A, Pirotte B, Rorive S, "et.al." Unusual CT features of dermoid cyst in the posterior fossa. Eur Radiol. 2002;12:27269.

7. Mendez J. Ventriculoatrial shunt blockage by previous positive contrast ventriculography. J Neurosurg. 1973;39(3):356-8. 